\title{
Uma análise da rede de auxiliares na expedição de Louis Agassiz ao Brasil (1865-1866)
}

\author{
An analysis of the network of assistants in Louis Agassiz's \\ expedition to Brazil (1865 - 1866)
}

\author{
ANDERSON PEREIRA ANTUNES \\ Casa de Oswaldo Cruz, Fundação Oswaldo Cruz | FIOCRUZ \\ LUISA MEDEIROS MASSARANI \\ Casa de Oswaldo Cruz, Fundação Oswaldo Cruz | FIOCRUZ
}

ILDEU DE CASTRO MOREIRA

Universidade Federal do Rio de Janeiro | UFRJ

RESUMO Uma expedição científica do século XIX contava, geralmente, com uma diversificada rede de auxiliares. Embora a participação destes indivíduos costumasse ser suprimida nas publicações de cunho científica, menções a suas contribuições eram recorrentes nos livros e diários de viagens mantidos pelos naturalistas. Neste artigo, analisamos a rede de auxiliares envolvida na Expedição Thayer, que visitou o Brasil entre 1865 e 1866 , liderada por Louis Agassiz, e observamos de que forma muitos membros das populações locais contribuíram para a realização e os resultados científicos alcançados pela Expedição Thayer.

Palavras-chave Louis Agassiz - expedições naturalistas - conhecimento local

\begin{abstract}
A nineteenth-century scientific expedition usually relied upon a diversified network of assistants. Although the participation of these individuals was usually suppressed in scientific publications, there were recurring mentions to their contributions in the travel books and diaries maintained by naturalists. In this article, we analyze the network of assistants involved in the Thayer Expedition that visited Brazil between 1865 and 1866, led by Louis Agassiz, and observe how many members of the local populations contributed to the realization and the scientific results achieved by the Thayer Expedition.
\end{abstract}

Keywords Louis Agassiz - scientific expeditions - local knowledge

\section{Introdução}

É possível observar, durante o século XIX, um intenso movimento de valorização das ciências e de suas aplicações tecnológicas. Este ambiente favorável às práticas científicas não se limitou apenas à Europa, mas se expandiu, ainda que em menores proporções, para as Américas. Foi um período fértil de viagens cientificas lideradas por naturalistas 
interessados em explorar diferentes partes do globo, em busca de respostas para as suas perguntas e de novos conhecimentos sobre a flora e a fauna que poderiam ter implicações econômicas. 0 Brasil surge, em meio a este cenário, como um dos principais destinos de muitos viajantes. 0 estabelecimento da Família Real portuguesa no Brasil, a partir de 1808, foi um dos estopins que começou a transformar as configurações políticas locais, abrindo as portas do país para um comércio material e intelectual mais intenso com outras nações. 0 novo clima político trazia consigo novas possibilidades. Além disso, o país era fonte de grande interesse científico por causa de sua enorme biodiversidade ainda em grande parte não inventariada. Nos relatos sobre o Brasil, muitos dos primeiros viajantes descreveram o cenário encontrado, de forma detalhada e exaustiva, ressaltando a exuberância da natureza local e a abundância de espécies. Em um período em que o debate acerca da origem das espécies passou à ordem do dia, os trópicos traziam a promessa de se tornar um local privilegiado para o estudo da questão. ${ }^{1}$

No entanto, organizar uma expedição científica era uma tarefa onerosa. Os recursos financeiros eram essenciais, pois, além de garantir o translado além-mar, também se faziam necessários para custear a movimentação por terra, estadia e a alimentação do naturalista e de seus acompanhantes, além da aquisição de instrumental e material de pesquisa e o pagamento de auxiliares. Em muitos casos, os recursos financeiros provinham do apoio oficial do governo do país de origem da expedição - geralmente interessado nas implicações econômicas que os resultados científicos da viagem poderiam gerar. Em outros casos o apoio tinha origem em um mecenas ou benfeitor particular. Uma outra opção, que ocorreu em certos casos, era custear a viagem com seus próprios recursos ou a partir da venda das coleções formadas, geralmente com o auxílio de um agente especializado neste tipo de comércio.

A obtenção dos recursos financeiros, no entanto, era apenas uma dentre uma série de etapas que antecedia a viagem. 0 naturalista viajante dificilmente trabalhava de forma solitária em suas explorações. Era preciso formar uma equipe e ter apoio de auxiliares locais. Usualmente a equipe de exploradores era formada pelo naturalista com o apoio daqueles que eram mais próximos aos seus círculos sociais. Colegas que trabalhavam nas mesmas instituições, que faziam parte das mesmas sociedades científicas ou com quem já haviam colaborado anteriormente eram os primeiros a serem incluídos na equipe. Mas a articulação de uma rede de auxiliares não se limitava a indivíduos próximos. Por meio de trocas de correspondências com naturalistas que já haviam realizado os mesmos percursos, com compatriotas residentes nos destinos de viagem ou com influentes moradores locais, era possível reunir indivíduos dispostos a participar ou colaborar com a viagem.

Após a chegada ao país de destino, era imprescindível que fossem contratados guias, mateiros, caçadores e ajudantes diversos. Muitas vezes escravos foram adquiridos ou alugados para auxiliar em tarefas necessárias para a realização das expedições. A equipe que constituía uma expedição científica era, comumente, heterogênea: contava desde naturalistas estrangeiros experientes até indivíduos locais que nunca haviam tido contato com um estrangeiro. A sociabilidade era, assim, uma parte importante da prática científica de campo realizada nessas viagens. ${ }^{2} \mathrm{~A}$ atuação da rede de contatos do viajante, estabelecida previamente ou ao longo de seu périplo, era decisiva para a conclusão com êxito de muitas de suas atividades.

Uma vez que se encontrava na região a ser explorada, o naturalista estrangeiro com frequência se defrontava com uma série de obstáculos. Além das diferenças de costumes e idiomas, precisava lidar com alfândegas, com situações políticas às vezes desfavoráveis, com condições de trabalho muitas vezes precárias, com o desconhecimento da geografia local e das diferentes espécies que faziam dela seu habitat, com o vasto e cansativo trabalho de coleta, preparação, embalagem e transporte de espécimes, só para citar algumas de suas preocupações cotidianas. Sua rede de auxiliares se fazia presente em quase todas as tarefas que faziam parte da expedição. Por isso, quanto mais diversificadas fossem as origens, habilidades e profissões de seus auxiliares, mais diversos eram os auxílios, sejam eles logísticos ou relacionados com conhecimentos locais, recebidos pelos naturalistas. Dentre as contribuições principais proporcionadas pelos auxiliares locais, Moreira cita:

A partir de vários desses escritos, pode-se estabelecer os principais tipos de contribuições do pessoal local: identificação, localização, coleta e nomenclatura de animais e plantas; preparação e preservação de 
espécimes; descobertas de "novas" espécies; análise de hábitos e usos de animais e plantas; conhecimentos geográficos, meteorológicos e de distribuição de animais e plantas; relatos antropológicos; indicação de locais mais favoráveis para pesquisa; domesticação de animais; e fabricação de instrumentos (inclusive para captura e preservação de animais). ${ }^{3}$

Apesar da importância destes auxiliares, suas participações são tratadas frequentemente com ambiguidade nos relatos e artigos escritos pelos naturalistas posteriormente às viagens. Enquanto em suas crônicas e diários não faltam menções e descrições mais ou menos detalhadas sobre as contribuições que receberam, artigos e textos voltados para o público científico geralmente omitem qualquer participação da população local. Segundo Camerini, ${ }^{4}$ a explicação para essa omissão tem a ver com as convenções específicas para a redação de artigos e trabalhos científicos, que valorizavam - e, ainda hoje, continuam a valorizar - características como a concisão e a objetividade, que acabavam por maximizar a relevância de seu autor, que não só assinava os artigos, mas também comumente batizava com seu nome, ou o de pessoas que queria homenagear, as espécies descritas e as teorias formuladas. Isto se traduziu em uma desvalorização social do trabalho realizado por estes auxiliares e, de acordo com Moreira, "contribuiu, entre outros fatores, para o surgimento da imagem social do cientista herói-desbravador que, sobrevivendo a imensos perigos, com esforço hercúleo e quase solitário, 'descobriu' grande quantidade de espécies novas de animais e plantas.." 5 .

No entanto, uma análise dos livros e diários de viagens - que se tornaram um gênero literário bastante consumido entre o público letrado, especialmente na Europa - nos revelam um cenário no qual o naturalista, muitas vezes, inclui descrições e opiniões pessoais sobre suas interações com a população local. A historiografia das viagens científicas, por sua vez, parece ter seguido, por muito tempo, a tendência dos próprios artigos e textos científicos, deixando em segundo plano as contribuições feitas pelas populações locais. Recentemente, seguindo um movimento historiográfico de maior valorização de conhecimentos locais, em oposição ao global, cada vez mais pesquisadores passaram a atentar para a importância das relações que os viajantes mantinham com as populações locais e de seu aprendizado com elas.

Em sua análise da expedição de Alfred Russel Wallace (1823 - 1913) ao Arquipélago Malaio, Camerini, ${ }^{6}$ destacou a importância da confiança mútua que existia entre o viajante inglês e seu auxiliar Ali, que servia de seu intérprete quando em contato com os povos nativos. Segundo a autora, sua mediação foi fundamental para que os caçadores locais se sentissem seguros em compartilhar o conhecimento que possuíam sobre o hábitat e os costumes das aves do paraíso que Wallace queria observar e capturar. Moreira, ${ }^{7}$ menciona contribuições importantes de habitantes locais a expedições feitas no Brasil por naturalistas de destaque como Charles Darwin (1809 - 1882), Alfred Wallace, Henry W. Bates (1825 - 1892) e Louis Agassiz (1807 - 1873). Com foco semelhante, Fan observou as relações existentes entre os naturalistas ingleses e seus auxiliares locais na cidade de Cantão durante a virada do século XVIII para o XIX. As redes formadas pelos viajantes nesta cidade asiática incluíam uma vasta gama de personagens, como artesãos, mercadores e jardineiros, com os quais adquiriam espécimes e aprendiam sobre seus usos nativos. 0 conhecimento prático dos habitantes locais era peça fundamental para os estudos botânicos, uma vez que os nativos possuíam amplo conhecimento sobre onde encontrar determinadas espécies e seus variados usos. 0 conhecimento de habitantes locais também era fundamental para garantir o acondicionamento, transporte e transplante adequados dos exemplares, em uma época em que a aclimatação de espécimes de flora era um tópico de grande importância utilitária, medicinal e comercial.

Em outra análise, Raj ${ }^{9}$ aponta para a vitalidade dos conhecimentos locais para a própria sobrevivência e bem-estar dos viajantes em terras estrangeiras, onde costumavam estar expostos a um clima, a uma alimentação e a doenças muito diferentes daquelas comuns em seus países natais. Sobre este tema, Raj afirma:

A sobrevivência europeia na região dependia do desenvolvimento de uma relação constante e duradoura entre mercadores, missionários e viajantes europeus e vários agentes regionais - governantes, mercadores, banqueiros e intérpretes, mas também trabalhadores experientes e sábios. No mundo do Oceano Índico, o conhecimento especializado, em particular aquele sobre botânica, medicina e alquimia, já se apresentava formalizado e em circulação da península arábica até a China, por meio de comunidades especializadas, cada uma com suas próprias regras de civilidade. ${ }^{10}$ 
A partir dos trabalhos destes autores é possível perceber como se dava a circulação de conhecimentos e saberes tradicionais entre as populações locais e os recém-chegados visitantes, que se apropriavam das informações adquiridas pelos habitantes ao longo de anos de observação e vivência naquelas regiões. Os residentes locais, como 0 malaio Ali que auxiliou Wallace no Arquipélago Malaio ou o guia Isidoro que, no Brasil, o ensinou a identificar árvores e seus usos, ${ }^{11}$ os habitantes indígenas nativos daquelas regiões, ou ainda os escravos que, embora emigrados de forma forçada, já habitavam e conheciam bem as regiões que os estrangeiros pretendiam explorar, tornavam-se elementos chave para o sucesso das expedições.

Segundo Subrahmanyam, ${ }^{12}$ esses indivíduos agiam como intermediários (go-betweens, no original), atuando como pontes entre os viajantes estrangeiros e o conhecimento local. As diferenças culturais e linguísticas existentes muitas vezes dificultavam ou até mesmo impossibilitavam a interação direta com a população. A desconfiança dos moradores em relação às intenções de seus visitantes também era outro empecilho para que pudesse haver, entre ambas as partes, uma comunicação aberta que permitisse o compartilhamento de informações. É neste cenário que surge o intermediário, caracterizado como aquele indivíduo que detém a capacidade de se comunicar com ambas as partes e de transitar entre ambos os mundos. A atuação do intermediário garantia ao viajante uma forma de ampliar ainda mais sua rede de contatos, garantindo assim acesso a auxiliares (e a seus conhecimentos) que estariam além do seu contato direto.

Tomando por pressupostos os achados destes autores percebemos que, embora as relações entre os viajantes e os habitantes locais, de variadas camadas sociais e profissionais, tenham sido fundamentais no trabalho de campo destes naturalistas, as convenções da escrita em ciência tornaram estes atores invisíveis em meio ao estilo rígido e objetivo de relatórios e artigos científicos. A escassez de relatos realizados pelos próprios auxiliares, que em alguns casos não dominavam a escrita ou pertenciam a comunidades que se comunicavam tradicionalmente por meio da oralidade, torna difícil a verificação de suas opiniões e sentimentos sobre suas relações com os viajantes, que são os principais narradores de sua própria história. Trazer para o foco a atuação destes personagens e as suas contribuições se torna, portanto, um grande desafio para os historiadores da ciência.

É com a intenção de contribuir com os estudos recentes sobre o papel dos auxiliares no trabalho de campo dos naturalistas Oitocentistas, que analisaremos caso específico da Expedição Thayer (1865 - 1866), liderada pelo naturalista de origem suíça Louis Agassiz (1807 - 1873). A justificativa para a escolha desta expedição se dá pelo fato de ter sido uma das expedições naturalistas ao Brasil do século XIX que envolveu o maior aparato de apoio logístico e a colaboração direta de um grande número de pessoas. A expedição teve um grande apoio financeiro, institucional e governamental, tanto por parte da iniciativa privada, quanto por parte de órgãos públicos norte-americanos e brasileiros. A comitiva contou com o envolvimento de mais de uma centena de auxiliares, mencionados nominalmente no relato escrito em conjunto por Louis Agassiz e sua esposa Elizabeth Cabot Agassiz (1822 - 1907), e publicado sob o título A Journey in Brazil (1868). A expedição coletou grande número de espécimes animais, em especial de peixes de todo o território brasileiro, que resultaram na identificação de centenas de novas espécies. ${ }^{13}$

\section{Louis Agassiz e a expedição Thayer}

Quando Agassiz deixou definitivamente a Europa pelos Estados Unidos, em 1847, seu nome já era reconhecido pela comunidade científica internacional. Em sua rede de contatos, já figuravam importantes figuras do mundo da História Natural, como os naturalistas Carl Friedrich von Martius (1794 - 1868), Alexander von Humboldt (1769 - 1859) e Georges Cuvier (1769 - 1832), que foram mentores e influências marcantes no pensamento científico de Agassiz. ${ }^{14}$ Von Martius proporcionou a Agassiz sua primeira oportunidade de estudar os peixes brasileiros, quando foi convidado para compilar um volume sobre as coleções realizadas por Johann Baptiste von Spix (1781 - 1826), então recém falecido. Selecta genera et species piscium (1829 - 1831) foi não apenas a primeira grande publicação de Agassiz, mas também um veículo pelo qual consolidou seu nome como um especialista em ictiologia. 
Com Cuvier, que era um dos maiores opositores de Jean-Baptiste de Lamarck (1744 - 1829) e de suas ideias sobre o desenvolvimento das espécies ao longo do tempo, Agassiz herdou uma visão estática da vida entre as grandes catástrofes e os atos isolados de criação. Acreditava, assim, que as espécies eram criadas por intenção divina da maneira como estavam destinadas a ser e que seriam incapazes de se transformar com o tempo. Já de Humboldt, Agassiz incorporou a formulação sobre a existência de províncias geológicas para propor a existência de províncias zoológicas, isto é, a ideia de que as espécies não eram apenas criadas por Deus, mas eram também designadas para habitar algumas regiões específicas, onde ficariam para sempre circunscritas.

Além de suas pesquisas biológicas, Agassiz também era amplamente reconhecido por seu estudo da glaciação, especialmente na Europa. Outro tema que marcou sua carreira científica foi o estudo das raças humanas. Na época, esta questão era um dos tópicos mais acaloradamente debatidos em um Estados Unidos da América em clima secessionista. ${ }^{15}$ Embora inicialmente mantivesse uma visão monogenista sobre a criação do Homem, sua inserção no debate norte-americano e a influência do médico Samuel Morton (1799 - 1851) foram alguns fatores que levaram a adesão de Agassiz ao poligenismo.

Foi com estas concepções científicas que Louis Agassiz partiu em direção ao Brasil em 1865. 0 périplo brasileiro tinha dois objetivos específicos: o estudo da glaciação no Hemisfério Sul e a coleta de espécies, particularmente peixes amazônicos. Com estes estudos, Agassiz pretendia reunir fatos que pudessem fortalecer a teoria criacionista-catastrofista que defendia, podendo provar que uma glaciação recente, no fim do período Terciário, teria causado uma extinção global, o que explicaria as diferenças entre as espécies que eram conhecidas pelos registros arqueológicos e aquelas criadas por Deus para habitar o período contemporâneo. Além disso, seu estudo dos peixes pretendia provar a especificidade da localização geográfica de cada espécie segundo províncias zoológicas determinadas, que poderiam ser explicadas apenas pela designação divina e não pela seleção natural. Da mesma forma como seu mentor, Cuvier, havia sido um ferrenho adversário de Lamarck, Agassiz assumia a posição de um dos principais antagonistas das ideias evolucionistas defendidas por Charles Darwin e Alfred Wallace.

Embora sua viagem ao Brasil tivesse, inicialmente, o objetivo de permitir algum tempo de descanso do trabalho que vinha realizando no Museu de Zoologia Comparada, que havia fundado na Universidade de Harvard, e uma oportunidade para recuperar sua saúde debilitada, seus planos logo se transformaram. A oferta de apoio financeiro de Nathaniel Thayer Jr. (1808 - 1883), empresário e filantropo de Massachusetts, transformou a pretendida viagem de férias em uma expedição científica. Com todos os custos de sua viagem, e de mais seis assistentes, pagos por seu benfeitor ${ }^{16}$, Agassiz organizou sua expedição ao Brasil.

Para compor sua equipe, contou com a participação de alguns dos funcionários do Museu de Zoologia Comparada e selecionou especialistas em diferentes áreas. Foram recrutados para a viagem o geólogo Charles Frederick Hartt (1840 - 1878), o ornitólogo Joel Asaph Allen (1838 - 1921), o conquiologista John Gould Anthony (1804 - 1877), o paleontólogo Orestes St. John, o artista Jacques Burkhardt (1818 - 1897) e o preparador de espécimes George Sceva. Agassiz também divulgou na Universidade de Harvard que pretendia alistar alguns estudantes para a expedição científica, com a condição de que estes custeassem seus gastos. Seis alunos ou ex-alunos se voluntariaram: Newton Dexter, William James (1842 - 1910), Edward Copeland, Thomas Ward (1884 - 1940), Walter Hunnewell (1844 - 1921), além do filho do mecenas da expedição, Stephen V. R. Thayer (1847 - 1871). Com a adição de sua esposa, ficou formada a equipe.

A comitiva deixou os Estados Unidos em $1^{\circ}$ de abril de 1865, a bordo do navio a vapor Colorado, que partiu de Nova lorque. A viagem foi cedida gratuitamente aos viajantes pelo presidente da Pacific Mail Steamship Company, mais um dos benfeitores do bem articulado Agassiz. As relações políticas de Agassiz, que não se restringiam ao governo norte-americano, mas incluíam, também, sua amizade com o Imperador D. Pedro II (1825 - 1891), a quem fora apresentado via correspondência pelo missionário James Cooley Fletcher (1823 - 1901), possibilitaram à expedição uma série de benefícios. Como veremos adiante, o relacionamento com figuras influentes na política brasileira, muitos dos quais agiram como intermediários, permitiu que Agassiz ampliasse sua rede de contatos de forma singular, conseguindo diversos auxílios para sua expedição. 
Muitos estudiosos não consideram a expedição de Agassiz bem-sucedida, por não ter conseguido provar suas hipóteses ou por não ter aproveitado bem os espécimes coletados, ${ }_{1}^{17}$ mas devemos lembrar que a Expedição Thayer conseguiu percorrer uma vasta extensão do solo brasileiro, articulou importantes alianças locais e levou de volta para 0 Museu de Zoologia Comparada um número estimado de cerca de 76 mil espécimes de animais, segundo seu relatório anual para 0 ano de $1866 .{ }^{18}$ Embora Agassiz seja ocasionalmente relegado a uma posição de menor importância, além de ser frequentemente associado com posições retrógradas e racistas, é preciso ter cuidado para não tratar a História da Ciência como um embate entre "vencedores" e "perdedores". Apesar de não ter conseguido refutar a teoria evolucionista, é preciso atentar para o fato de que Agassiz fez contribuições científicas relevantes no estudo das glaciações na Europa e, segundo Irmscher, ${ }^{19}$ muitos de seus artigos científicos na área de ictiologia possuem informações que ainda têm interesse para os cientistas contemporâneos.

\section{Os auxiliares na expedição Thayer}

Para analisar a rede de auxiliares envolvida na Expedição Thayer, utilizamos de algumas fontes primárias, que serão mencionadas ao longo do artigo. A principal delas foi o relato de viagem redigido pelo casal Agassiz. Embora outros membros do grupo tenham mantido anotações regulares, como foi o caso de William James ${ }^{20}$ e do geólogo Charles Hartt, ${ }^{21}$ o relato dos Agassiz é o mais completo sobre o itinerário e os relacionamentos dos expedicionários com a população local. É necessário enfatizar que, por se tratar de anotações redigidas com o propósito de serem publicadas para um público determinado, estamos diante de uma história que nos é contada pela perspectiva dos Agassiz.

Após uma leitura minuciosa de $A$ Journey in Brazil, identificamos 167 auxiliares que foram ali mencionados. Em sua maioria, as menções são feitas nominalmente a indivíduos específicos, embora também sejam citadas instituições e existam algumas citações genéricas a grupos de indivíduos não identificados individualmente. Devido a heterogeneidade de indivíduos citados, criamos categorias para sistematizar as informações relacionadas a estes personagens, utilizando como critério o tipo de serviço prestado à expedição. Chegamos à seguinte proposição: utilizar o vocábulo auxiliar de forma genérica para caracterizar todo o conjunto de indivíduos que contribuíram para a expedição, uma vez que seu significado engloba tudo "que ou o que presta assistência a outrem na realização de alguma atividade". 22 Dentro deste grupo dos auxiliares, incluímos dois subgrupos diferentes: o dos ajudantes e o dos colaboradores. 0 "ajudante" é constituído por aqueles indivíduos hierarquicamente inferiores no contexto da expedição, que contribuíram de forma inespecífica com auxílios que poderiam ter sido realizados de forma igualmente satisfatória por outros indivíduos. Colaborador é utilizado para definir aquela "pessoa que trabalha com outra em iguais circunstâncias de iniciativa". ${ }^{23}$ Neste caso estão os indivíduos que contribuíram com auxílios específicos e individuais, que dificilmente poderiam ter sido substituídos por outras pessoas. Dividimos a classe colaborador em três tipos de colaborações específicas: o colaborador logístico, o colaborador científico e o colaborador de conhecimento tradicional ou local, entendido aqui como aquele indivíduo possuidor de conhecimentos adquiridos, em geral de forma empírica, por conta dos hábitos e costumes, à experiência própria ou coletiva ou que estão inseridos na cultura local, em oposição aos conhecimentos associados à formação especializada e aos métodos e critérios da ciência. Em categoria distinta, intitulada referência e motivação, traduzimos a necessidade de adicionar um grupo relacionado àqueles indivíduos que foram citados pelos viajantes como fontes de inspiração e motivação para a realização da jornada.

Como mostra o gráfico 1, no subconjunto dos ajudantes mencionados no livro, encontramos 22 indivíduos, sendo que 10 deles não são identificados nominalmente; os colaboradores, por sua vez, constituem um grupo de 116 pessoas no qual apenas sete não são identificadas nominalmente, sendo 75 colaboradores científicos, 35 colaboradores logísticos e seis colaboradores de conhecimentos tradicionais; por fim, o grupo de indivíduos mencionados por referência e motivação constitui um total de 29 auxiliares, todos identificados nominalmente. 


\title{
Gráfico 1: Número de auxiliares por categoria
}

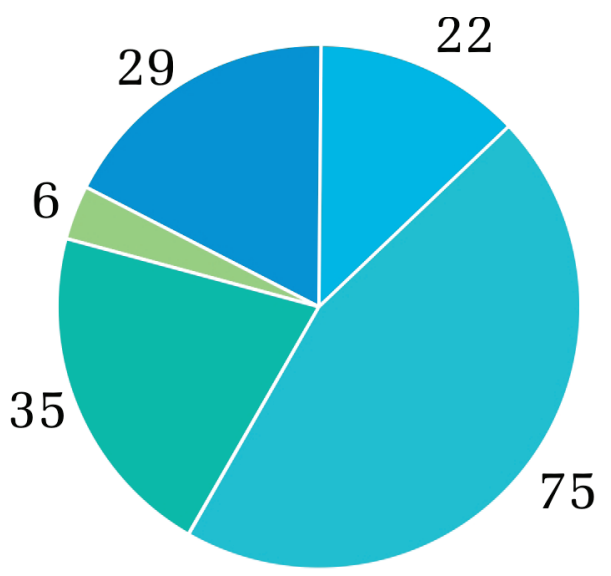

\section{Ajudantes}

Colaboradores Científicos

\section{Colaboradores Logísticos}

\section{Colaboradores de Conhecimentos Tradicionais}

\author{
Referência e Motivação
}

A articulação dessa extensa rede de auxiliares locais teve início no Rio de Janeiro. Quando chegou ao Brasil, Agassiz estrategicamente reservou os primeiros três meses para sua estada na capital do Império, local privilegiado para fomentar laços com importantes figuras políticas, dentre as quais merece destaque o próprio D. Pedro II. 0 Imperador foi um dos mais importantes intermediários na rede de auxiliares de Agassiz, como se reconheceu em diversas passagens do livro de viagem. 0 interesse pessoal do monarca pelas ciências, ${ }^{24}$ seu relacionamento e auxílio a outros naturalistas da época, e 0 contato anterior com Agassiz, ${ }^{25} 0$ aproximavam da Expedição Thayer e de seus membros. 0 encontro no Imperial Observatório, em 25 de abril de 1865, para assistirem juntos a um eclipse solar foi 0 apenas o primeiro de uma série de encontros que solidificaram o interesse do Imperador em auxiliar Agassiz e sua expedição. Embora tenha suprimido, a pedido do próprio Pedro II, muitas das menções que fazia ao seu auxílio em seu manuscrito original, ainda assim são muitas as passagens do livro em que o casal expressa sua gratidão pelo apoio recebido, como neste trecho:

O fato de que o Imperador do Brasil estava profundamente interessado em todos os empreendimentos científicos e que havia expressado uma calorosa simpatia com meus esforços de estabelecer um grande museu zoológico neste país, me auxiliando inclusive com o envio de coleções feitas expressamente sob suas ordens para este propósito, foi um incentivo adicional. Eu sabia que o chefe do governo me daria todas as facilidades para que eu realizasse minhas investigações. ${ }^{26}$

No entanto, entre todos os auxílios recebidos pelo imperador brasileiro, Agassiz destaca que o mais importante de todos foi o contato com um naturalista e engenheiro militar, o Major João Martins da Silva Coutinho (1830-1889), e a autorização para que ele acompanhasse a expedição. Em correspondência endereçada à D. Pedro II, Agassiz afirmou:

Permita-me adicionar que, de todos os favores com os quais Vossa Majestade coroou esta viagem, o mais precioso tem sido a presença do Major Coutinho, cuja familiaridade com tudo aquilo que se relaciona ao Amazonas tem sido uma fonte inexaurível de informações importantes e indicações úteis, com as quais a perda de tempo com excursões irremuneráveis tem sido evitada. A cooperação do major durante esta jornada tem sido das mais diligentes, ele se aplicou à zoologia como se as ciências físicas não tivessem sido até então o seu objeto especial de estudo. Ao mesmo tempo, realizou inúmeras observações termométricas, barométricas e astronômicas, as quais serão importantes adições ao que já se conhece sobre a meteorologia e topografia dessas províncias. ${ }^{27}$

Nascido em São João da Barra, no Rio de Janeiro, em 1830, Silva Coutinho se formou na Escola Militar como bacharel em matemática e ciências físicas. ${ }^{28}$ Durante sua carreira no Corpo de Engenheiros do Exército, Coutinho se dedicou a duas atividades: lecionar na Escola Central do Exército e participar de comissões de exploração e reconhe- 
cimento de território. Por diversas vezes, foi enviado para províncias do norte e nordeste, e ali visitou e inspecionou diversas regiões, seus principais rios e afluentes e sua geografia urbana. Coutinho era um homem de grande capacidade de observação e com uma preocupação constante acerca do possível uso industrial dos produtos da natureza. Em seus arquivos, hoje guardados no Museu Paraense Emílio Goeldi, ${ }^{29}$ pode-se perceber que, por todas as regiões que passava, fazia apontamentos sobre os gêneros ali produzidos, as importações e exportações, o clima, a distribuição da população, os meios de transporte, a diversidade de fauna e flora e os usos que delas faziam os habitantes locais. Em seus relatórios, também são constantes as anotações sobre os hábitos e culturas indígenas.

Coutinho voltava de uma viagem ao nordeste brasileiro quando, em um encontro com Pedro II, conheceu Louis Agassiz. Por intermédio do Imperador, foi designado para acompanhar a Expedição Thayer na posição de guia, devido ao seu vasto conhecimento sobre as províncias que seriam visitadas. Seu conhecimento da geografia e da natureza do país provou ser valioso para Agassiz, que pode contar com sua ajuda no planejamento do trajeto da missão e na escolha de locais para exploração e coleta. Desde a partida do Rio de Janeiro, e até o término da viagem, Coutinho seguiu juntamente com Agassiz e sua esposa, formando o grupo principal da expedição, enquanto os outros membros eram divididos em equipes menores para possibilitar exploração de uma área maior do país.

Além de fornecer informações logísticas, o Major também foi um auxiliar muito ativo na coleta de espécimes. Segundo as informações do relatório anual de 1866 do Museu de Zoologia Comparada de Harvard, ${ }^{30}$ Coutinho foi responsável pela coleta de um total de 6.332 espécimes, sendo a maioria de peixes amazônicos, o que o torna quinto maior coletor da expedição, atrás apenas do próprio Agassiz, de William James, Stephen Thayer e do naturalista francês Jean-Baptiste Dieudonné Bourget. Este último era dono de uma loja de objetos de História Natural na Rua do Ouvidor, no Rio de Janeiro, ${ }^{31}$ e foi contratado para acompanhar a expedição como coletor.

Também é interessante notar o auxílio de Coutinho como intermediário entre os viajantes estrangeiros e as populações locais. Durante suas passagens pelas regiões que visitou em expedições anteriores, o Major havia feito contato com diversas camadas da população. Em função desse seu extenso conhecimento dos habitantes locais, ele intermediou a relação de Agassiz com eles, fazendo ampliar a rede de auxiliares da expedição. Em especial, destaca-se a sua experiência com as populações indígenas, com as quais se comunicava na língua geral. Seu trabalho foi elogiado no diário de viagem:

Temos a esperança de que algum dia, o major Coutinho, que, enquanto fazia suas explorações como engenheiro nos rios amazônicos também fez um cuidadoso estudo das tribos que viviam nas suas margens, irá um dia publicar os resultados de suas investigações. É a ele que devemos a maior parte das informações que temos coletado sobre este tema [os indígenas]. ${ }^{32}$

Sobre a versatilidade do engenheiro, Elizabeth escreveu:

Enquanto o Sr. Agassiz se ocupava com as coleções zoológicas, o Major Coutinho fazia investigações geológicas, meteorológicas e hidrográficas. Sua cooperação constante é inestimável e o Sr. Agassiz abençoa o dia em que, ao se encontrarem por acaso no Palácio, sugeriu a ideia de adicioná-lo à expedição. Não apenas suas realizações científicas, mas seu conhecimento da língua indígena (língua geral) e sua familiaridade com os habitantes fazem dele um importante assistente. Com sua ajuda, o Sr. Agassiz já iniciou uma espécie de diário científico, no qual, ao lado do nome científico de cada espécime inserida pelo Professor, o Major Coutinho registra o nome popular, obtido através dos índios, com tudo o que eles podem nos dizer sobre seus hábitos e habitats. ${ }^{33}$

0 Major Coutinho também auxiliou na apresentação dos viajantes aos governantes das regiões. Por intermédio de Pedro II, os presidentes das províncias que seriam visitadas pela expedição foram avisados previamente da chegada dos naturalistas e requisitou-se que estes fossem auxiliados quando possível. Em uma transcrição de carta enviada ao próprio Imperador, Agassiz agradece profusamente os benefícios que conseguiu: 
Não posso deixar passar esta ocasião sem expressar minha gratidão por todas as facilidades que recebi para minha exploração e que devo à bondade de Vossa Majestade. Desde os presidentes até os mais humildes empregados das províncias que visitei, todos competiram entre si para tornar meu trabalho mais fácil, e a Companhia de Navegação do Amazonas mostrou-me extrema generosidade. Por fim, Vossa Majestade, a generosidade com a qual colocou-me a disposição um navio de guerra permitiu-me reunir coleções que, sem tão amplo e rápido meio de transporte, teriam permanecido completamente inacessíveis. Permita-me adicionar, ainda, que de todos os favores com as quais Vossa Majestade concedeu a esta viagem, o mais precioso tem sido a presença do Major Coutinho, cuja familiaridade com tudo aquilo que se refere ao Amazonas tem sido uma inexaurível fonte de informações importantes e úteis conselhos, de forma que a perda de tempo com excursões infrutíferas foi evitada. ${ }^{34}$

Em diversos trechos de seu livro de viagem, é possível encontrar passagens onde Agassiz descreve detalhadamente o seu relacionamento com a elite governante local. Quando chegou ao Pará, por exemplo, os viajantes já eram esperados pelo presidente da província, José Vieira Couto de Magalhães (1837 - 1898), que foi um político, militar, escritor e folclorista brasileiro, e também presidente das províncias de São Paulo, Mato Grosso e Goiás. A primeira excursão que fizeram pela região foi planejada pelo próprio Couto de Magalhães.

Antônio Epaminondas de Melo (? - 1885), presidente da província do Amazonas, foi outro governante local engajado no auxílio à expedição. Além de ter hospedado os viajantes em sua casa, Epaminondas de Melo também reuniu um grupo composto por seu secretário e alguns moradores locais para, juntos, fazerem excursões pela província. Em Manaus, formou uma comitiva junto com o seu secretário e com o político Aureliano Cândido Tavares Bastos (1839 1875) para acompanhar os naturalistas em sua exploração pelos arredores do Rio Negro. Desta reunião, resultou uma vasta coleta de espécimes, pelos quais Agassiz agradeceu em passagens do livro de viagem.

Na província do Ceará, à época gerida por Francisco Inácio Marcondes Homem de Melo (1837 - 1918), Agassiz relata que as coleções de palmeiras e peixes, que adquiriu no local, foram custeados pelo próprio presidente. ${ }^{35}$ Outro exemplo de apoio logístico importante veio de Manuel Antonio Pimenta Bueno, que era amigo pessoal do Major Coutinho. Como gerente da Companhia de Navegação do Amazonas, possuidora da linha de vapores que fazia o trajeto entre Pará e Tabatinga, ele tornou disponível um dos navios da companhia para a expedição. Possivelmente esta ação teve 0 incentivo de Pedro II e a anuência do Barão de Mauá, dono da companhia. Segundo Agassiz:

Para que fôssemos perfeitamente independentes, e pudéssemos parar onde desejássemos para fazer coletas, a companhia colocou a nossa disposição um vapor durante o período de um mês para viajarmos do Pará até Manaus. Não haverá nenhum outro passageiro além de nós, e o vapor está provido de tudo o que é necessário para toda a tripulação durante este período: alimentos, serviços, etc. Acho que é justo afirmar que em nenhuma outra parte do mundo poderia uma empreitada científica privada ser recebida com maior cordialidade ou receber maior hospitalidade do que tem recebido a presente expedição. ${ }^{36}$

Além disso, Pimenta Bueno reuniu também uma coleção de peixes que Agassiz julgou ser de grande valor. ${ }^{37}$

Em termos de coleta de espécimes, também é interessante destacarmos os colaboradores científicos mencionados no relatório anual de 1866, que não pertenciam ao corpo original da expedição vindo dos EUA e que atuaram no Brasil. ${ }^{38} 0$ relatório do museu lista os principais responsáveis pelas coleções recebidas. Foram eles: Major Coutinho, Bourget, Antonio de Lacerda, Talisman, D. Pedro II, Dr. Milcher, M. Naves, Col. Bentos, Dr. Couto de Magalhães, Dr. Castro, M. Vinhas, Sr. Honório, Albuquerque, Dr. Teuscher e Dr. Nägeli. São citados ainda, como colaboradores na coleta de espécimes: Dr. Cotting e Mr. Anthony, bem como a colaboração de Burkhardt com os desenhos de peixes e de outros animais, além de pessoas e de locais visitados, que atingem cerca de oito centenas e que fazem hoje parte do acervo da Biblioteca Ernst Mayr, da Universidade de Harvard. Possivelmente Louis Agassiz destacou no relatório aqueles colaboradores mais próximos e que ajudaram com a coleta de um número maior de espécimes. Mas há claramente uma síntese grande neste relato. Por exemplo, no caso dos peixes recolhidos no Rio de Janeiro (5.547 espécimes e 317 espécies) apenas o nome de Louis Agassiz aparece 
no relatório, embora se saiba que ele contou com um número grande de colaboradores nesta tarefa, muitos dos quais aparecem mencionados no livro de viagem.

A seguir, procedemos a uma identificação quase completa dos colaboradores científicos citados no relatório anual de 1866 e de suas contribuições principais:39 (1) Antônio Francisco de Lacerda (1834-1885), engenheiro da Bahia, formado nos EUA e, juntamente com seu irmão Augusto, responsável por diversas obras em Salvador, entre as quais o famoso Elevador Lacerda (1873). Ele deu importante apoio logístico e científico à expedição em especial na coleta de mamíferos, pássaros, répteis, peixes, insetos na Bahia; (2) Jean-Baptiste Dieudonné Bourget, naturalista já mencionado, com a coleta de mamíferos, répteis, peixes, insetos e crustáceos em várias regiões; (3) D. Pedro II: coleções de peixes e insetos do Rio de Janeiro. Encomendou, também, que se recolhessem coleções de peixes no Rio Grande do Sul; (4) Major Coutinho: coleta de mamíferos, pássaros, répteis e peixes na Amazônia; (5) Talisman Augusto Figueiredo Vasconcelos, funcionário da Companhia de Navegação do Amazonas no Pará, e indicado por Pimenta Bueno para acompanhar a expedição. Coleta de mamíferos, répteis, peixes e insetos na Amazônia; (6) Dr. Milcher: doutor José da Gama Malcher (1814 - 1882), erroneamente grafado como Milcher, que foi médico e político paraense, tendo sido vice-presidente da província do Pará. Coleta de pássaros; (7) M. Naves: Identificação desconhecida. Coleta de répteis e peixes no Amazonas (Jatuarana e Lago Januari); (8) Col. Bentos, Tenente-Coronel Bento José de Almeida, de Óbidos, no Pará: coleta de répteis e peixes no Pará; (9) Dr. Couto de Magalhães: coleta de peixes no Pará; (10) Dr. Castro, médico Francisco da Silva Castro (1815 - 1899), de Belém, e que foi inspetor local de saúde pública: coleta de insetos no Pará; (11) Dr. Teuscher, Reinhold Teuscher, médico alemão que trabalhava cuidando dos escravos de cinco fazendas do Barão de Nova Friburgo, em Cantagalo, no Rio de Janeiro: coleta de insetos em Cantagalo; (12) M. Vinhas, João Torquato Galvão Vinhas, comerciante português, residente em Porto de Moz. Coleta de peixes no Pará; (13) Sr. Honório, Antônio Honório Ferreira foi inspetor técnico da Província de Goiás e colaborou com a expedição no Amazonas. Ofereceu sua residência em Manaus para Agassiz. Coleta de peixes na Amazônia; (14) Sr. Albuquerque, provavelmente o senador do Império Antônio Coelho de Sá e Albuquerque (1821 - 1868). Coleta de peixes no Rio Grande do Sul, possivelmente por encomenda de D. Pedro II; (15) Dr. Nägeli, o médico Henrique Naegeli, doutor pela Universidade de Zurique e atuante no Rio de Janeiro entre 1862 e $1877^{40}$. Foi citado como importante naturalista do Rio de Janeiro por Louis Figuier. ${ }^{41}$ Coleta de equinodermas no Rio de Janeiro.

Entre os diversos colaboradores de conhecimentos tradicionais, vale destacar o papel de Alexandrina, que serviu de criada do grupo durante sua residência em Tefé. Embora inicialmente tenha sido chamada para realizar tarefas domésticas, Alexandrina logo demonstrou habilidades e capacidade de aprendizado que muito auxiliaram os viajantes.

\begin{abstract}
Alexandrina demonstrou ser uma valiosa adição ao grupo, não apenas por um ponto de vista doméstico, mas também científico. Ela aprendeu muito bem a preparar e limpar esqueletos de peixes e se faz bastante útil no laboratório. Além disso, ela conhece muitos caminhos pela floresta e me acompanha em todas as minhas excursões botânicas. Com a percepção aguçada de alguém cujo único treinamento foi através dos sentidos, ela é muito mais rápida do que eu em discernir mesmo os menores exemplares de plantas com frutos ou flores. E agora que ela sabe o que eu estou procurando, ela é uma assistente muito eficiente. Ágil como um macaco, ela não pensa duas vezes antes de subir ao topo de uma árvore para me trazer um galho com flores; e aqui, onde muitas das árvores crescem até alturas consideráveis antes de começarem seus galhos, uma auxiliar como ela é muito importante. ${ }^{42}$
\end{abstract}

Com os índios, além de refeições e de locais para descanso durante a noite, Agassiz também conseguiu auxílio para ampliar suas coleções. Com grande habilidade de caça e pesca e profundos conhecedores das regiões onde habitavam, Agassiz relatou que os indígenas logo se tornaram exímios coletores para a expedição, responsáveis pela contribuição de grande número de espécimes. 0 reconhecimento do papel destes auxiliares nativos, assim como a importância do Major Coutinho como intermediário entre os viajantes e os habitantes locais, são destacados pelo casal Agassiz em diversos trechos do diário de viagem. 
Devido a sua ampla rede de auxiliares e ao seu grande renome como naturalista, a notícia da vinda de Agassiz e seu grupo chegava nas cidades antes dos próprios viajantes. Para sua surpresa, geralmente eram recebidos pelos moradores locais já com grandes coleções de peixes prontos para serem desenhados, preparados, catalogados e figurarem nas coleções científicas da expedição. Elizabeth reconhece a importância e expressa sua gratidão pelo trabalho das pessoas que os auxiliavam na coleta de peixes em um trecho do livro:

O fato é que, não apenas aqui, mas em cada cidade onde paramos em nossa subida pela costa, o desejo cordial e a disposição do povo em ajudar no trabalho tem possibilitado a Agassiz juntar coleções que teriam sido impossíveis de reunir em tão pouco tempo. Se ele obtiver sucesso nesta expedição, é tanto devido a cordialidade dos próprios brasileiros e ao interesse que eles têm sobre os objetos que são tão caros à Agassiz, quanto aos esforços do próprio e de seus companheiros. ${ }^{43}$

\section{Considerações finais}

A realização de uma viagem científica era uma tarefa onerosa, que demandava planejamento, financiamento, infraestrutura, apoio logístico e científico. Além disso, a ciência praticada em campo por naturalistas como Agassiz e sua equipe era uma atividade fundamentalmente social, que dependia da articulação de uma ampla rede de auxiliares. No caso específico da Expedição Thayer, um dos principais auxílios conquistados por Agassiz foi apoio do governo brasileiro possibilitado, principalmente, por meio de sua amizade com Pedro II. A relação entre o monarca e o naturalista foi uma condição importante para ampliar a rede de contatos da expedição e estendê-la para importantes autoridades locais.

Para além deste apoio oficial, o auxílio das populações locais foi muito relevante, e o casal Agassiz reconhece 0 valor destas colaborações em diversas passagens de seu relato conjunto. A cooperação da população nativa, em muitas situações foi possibilitada pela atuação de intermediários, em especial do Major Coutinho. A partir de sua experiência em viagens anteriores às regiões visitadas e com seu conhecimento sobre as culturas indígenas, assim como sua capacidade de se comunicar por meio de língua geral, o Major foi uma figura fundamental para fomentar laços de amizade e confiança, que possibilitaram a colaboração e a troca de informações. Observando a rede de auxiliares de Agassiz, foi possível perceber o quão maciçamente articulada foi a sua expedição e como sua rede de auxiliares foi tanto ampla como heterogênea, com indivíduos oriundos de diversas camadas da população, auxiliando de formas variadas e em praticamente todos os momentos da viagem.

Com esta pesquisa, acreditamos ter sido possível contribuir com a perspectiva crescente em estudos de história da ciência que se voltam para os aspectos sociais das expedições naturalistas e para a contribuição não só logística, mas também do significativo aporte de conhecimentos empíricos por parte dos habitantes locais. Olhar para os auxiliares envolvidos com a Expedição Thayer possibilita a compreensão de que o trabalho realizado pelos naturalistas, especialmente nas expedições de maior vulto, foi um empreendimento com ampla articulação social, no qual a mobilização das populações locais se constituiu em uma etapa fundamental para a consecução de suas finalidades científicas. 


\section{Notas e referências bibliográficas}

Anderson Pereira Antunes é doutorando no Programa de Pós-Graduação em História das Ciências e da Saúde, da Casa de Oswaldo Cruz, Fundação Oswaldo Cruz e bolsista da Coordenação de Aperfeiçoamento de Pessoal de Nível Superior (Capes).E-mail: anderson.p.antunes@gmail.com.

Luisa Medeiros Massarani é doutora em Gestão, Educação e Difusão em Biociências e pesquisadora do Núcleo de Estudos da Divulgação Científica, Museu da Vida, Casa de Oswaldo Cruz, Fundação Oswaldo Cruz. E-mail: lumassa@fiocruz.br.

Ildeu de Castro Moreira é doutor em Física e professor do Instituto de Física da Universidade Federal do Rio de Janeiro. E-mail: ildeucastro@gmail.com.

1 Cf. MOREIRA, I. C.. 0 escravo do naturalista. Ciência hoje, v. 31, n. 184, jul. 2002.

2 Cf. CAMERINI, J. R. Wallace in the field. Osiris, 2nd series, 1996. Disponível em: < http://www2.warwick.ac.uk/fac/arts/history/students/modules/hi916/ week5/camerini_wallace_in_the_field.pdf> Acesso em: 14 nov. 2014; HODACS, H. Linnaeans outdoors: the transformative role of studying nature "on the road" and outside. British Journal of History of Science, 2010. Disponível em: < http://www2.warwick.ac.uk/fac/arts/history/ghcc/eac/people/hodacs/ hanna hodacs linneans outdoors.pdf> Acesso em: 14 nov. 2014; MACHADO, M. H. P. T. Brazil through the eyes of William James: letters, diaries, and drawings, 1865-1866. Cambridge: Harvard University Press, 2006; RAJ, K.. Surgeons, fakirs, merchants and craftsmen: making L'Empereur's Jardin in early modern South Asia. In: RAJ, K. Relocating modern science. New York: Palgrave Macmillan, 2007; SUBRAHMANYAM, S. Between a rock and a hard place. Some afterthoughts. IN: SCHAFFER; ROBERTS; RAJ; DELBOURGO (ed.). The brokered world. Estados Unidos: Science History Publications, 2009.

3 MOREIRA, op. cit., 2002, p. 42.

4 CAMERINI, op. cit., 1996.

5 MOREIRA, op. cit., 2002, p. 47

6 CAMERINI, op. cit., 1996.

7 MOREIRA, op. cit., 2002

8 FAN, Fa-ti. Science in a Chinese entrepôt: British naturalists and their Chinese associates in Old Canton. Osiris, 2nd series, v. 18, Science and the City, 2003, p. 60-78.

9 RAJ, K. Relocating modern science. New York: Palgrave Macmillan, 2007.

10 RAJ, op. cit., 2007. p. 30, tradução livre.

11 MOREIRA, op. cit., 2002, p. 45.

12 SUBRAHMANYAM, op. cit., 2009.

124 MUSEUM OF COMPARATIVE ZOOLOGY. Annual report of the trustees of the Museum of Comparative Zoology, at Harvard College, in Cambridge, together with the report of the director, 1866. Boston: Wright \& Potter, 1867. Disponível em: <http://biodiversitylibrary.org/page/41111987> Acesso em: 11 jan. 2015.

14 Cf. KURY, L. A sereia amazônica dos Agassiz: zoologia e racismo na Viagem ao Brasil. Revista Brasileira de História. São Paulo, v. 21, n. 41, 2001, p. 157172. Disponível em: < http://run.edu.ng/media/2566903943121.pdf > Acesso em: 14 nov. 2014.

15 Cf. GRAY, W.; HOFSTADTER, R. Panorama da História dos Estados Unidos. Distrito Federal: Embaixada Americana no Brasil, 1970.

16 Os custos totais, estimados por Agassiz anteriormente à sua viagem, somavam o que, ajustados para valores atuais, equivaleriam a cerca de $R \$ 75.000,00$ por viajante.

17 Cf. IRMSCHER, C. Louis Agassiz: creator of American Science. Boston/New York: Houghton Mifflin Harcourt, 2013; VANZOLINI, P. E. Brasil dos viajantes: a contribuição zoológica dos primeiros naturalistas viajantes no Brasil. Revista USP, n. 30, p. 190-238, 1996. Disponível em: < http://www.revistas.usp.br/ revusp/article/view/25918/27650> Acesso em: 16 jan. 2015.

18 MUSEUM OF COMPARATIVE ZOOLOGY. Op. cit., 1867.

19 IRMSCHER, op. cit., 2013, p. 3.

20 JAMES, W. Louis Agassiz. Cambridge: University of Harvard Press, 1896. Disponível em: < https://archive.org/details/louisagassizword00jame> Acesso em: 14 nov. 2014.

21 HARTT, C. F. Scientific results of A Journey in Brazil by Louis Agassiz and his travelling companions. Geology and physical geography of Brazil. Boston: Fields, Osgood \& Co., 1870. Disponível em: < https://archive.org/details/geographyofbrazilO0hartrich> Acesso em: 30 dez. 2014.

22 DICIONÁRIO PRIBERAM DA LÍNGUA PORTUGUESA. Auxiliar. Disponível em:<http://www.priberam.pt/DLPO/auxiliar> Acesso em: 14 nov. 2014.

23 Idem. Colaborador. Disponível em: <http://www.priberam.pt/DLPO/colaborador> Acesso em: 14 nov. 2014

24 Cf. SCHWARCZ, L. M. As barbas do Imperador: D. Pedro II, um monarca nos trópicos. São Paulo: Companhia das Letras, 1998.

25 As correspondências entre o Imperador e Agassiz foram publicadas no volume 13 do anuário do Museu Imperial. Cf. MINISTÉRIO DA EDUCAÇÃO E CULTURA. Anuário do Museu Imperial de Petrópolis, vol. 13. Petrópolis: Museu Imperial, 1952.

26 AGASSIZ, L.; AGASSIZ, E. C. A Journey in Brazil. Boston: Ticknor and Fields, 1868. Disponível em: <https://archive.org/details/journeyinbrazil00agasiala> Acesso em: 23 nov. 2013. p. v, tradução livre.

27 Idem, p. 384, tradução livre.

28 SILVA, M. J.; FERNANDES, A. C. S.; FONSECA, V. M. M. Silva Coutinho: uma trajetória profissional e sua contribuição às coleções geológicas do Museu Nacional. História, Ciências, Saúde-Manguinhos, v. 20, n. 2, 2013, p. 457-479. Disponível em: < http://www.scielo.br/scielo.php?script=sci_arttext\&pid $=$ S0104-59702013000200457> Acesso em: 6 jan. 2015

290 acervo do Major Coutinho foi inventariado e publicado pelo Museu Paraense. Cf. SILVEIRA, H. A. da (coord.). Inventário analítico do arquivo João Martins da Silva Coutinho. Belém: Museu Paraense Emílio Goeldi; IBM Indústria, Máquina e Serviços Ltda, 1984. 
30 MUSEUM OF COMPARATIVE ZOOLOGY, op. cit., 1867.

31 HARING, C. G. Almanak administrativo, mercantil e industrial da Corte e província do Rio de Janeiro para o anno de 1863. Rio de Janeiro: Eduardo \& Henrique Laemmert, 1863. p. 603. Disponível em: < http://objdigital.bn.br/acervo_digital/div_periodicos/almanak/al1863/00000003.html > Acesso em: 6 jan. 2015.

32

AGASSIZ; AGASSIZ, Op. cit., 1868, p. 321, tradução livre.

33 Idem, p. 146, tradução livre.

34 Idem, p. 384, tradução livre.

35 Idem, p. 462.

36 Idem, p. 145, tradução livre.

37 Idem, p. 145.

38 MUSEUM OF COMPARATIVE ZOOLOGY, op. cit., 1867, p. 4.

39 Idem.

40 CARDOSO, J. A. S. Almanack administrativo, mercantil e industrial da corte e província do Rio de Janeiro, inclusive a cidade de Santos, da província de São Paulo, para o anno de 1877. Rio de Janeiro: Eduardo e Henrique Laemmert, 1877. Disponível em: < http://memoria.bn.br/DocReader/cache/2996409963495/ I0042369-2Alt $=002104 \mathrm{Lar}=001350 . J P G>$ Acesso em: 2 jan. 2015, p 691.

41 FIGUER, L. Primitive Man. London: Chapman and Hall, 1870, p 299.

42 AGASSIZ; AGASSIZ, Op. cit., 1868, p. 236, tradução livre.

43 Idem, p. 238, tradução livre.

Recebido em Outubro de 2015. Aprovado para publicação em Maio de 2016] 